\title{
Humanitarian Engineering Design for Health Challenges: An Inter-faculty Service Based Learning Model
}

\author{
Yara Najem \\ Faculty of Health Sciences and the Maroun Semaan Faculty of Engineering and Architecture \\ American University of Beirut \\ P.O. Box 11-0236, Riad El Solh - Beirut: 1107 - 2020, Lebanon \\ yen02@aub.edu.lb \\ Imad H. Elhajj* \\ Electrical and Computer Engineering Department \\ American University of Beirut \\ P.O. Box 11-0236,Riad El Solh - Beirut: 1107 - 2020, Lebanon \\ ie05@aub.edu.lb \\ Zaher Dawy \\ Electrical and Computer Engineering Department, \\ American University of Beirut, \\ P.O. Box 11-0236,Riad El Solh - Beirut: 1107 - 2020, Lebanon \\ zd03@aub.edu.lb \\ Aline Germani \\ Center for Public Health Practice \\ American University of Beirut \\ P.O. Box 11-0236, Riad El Solh - Beirut: 1107 - 2020, Lebanon \\ ag24@aub.edu.lb \\ Hala Ghattas \\ Center for Research on Population and Health \\ American University of Beirut \\ P.O. Box 11-0236, Riad El Solh - Beirut: 1107 - 2020, Lebanon \\ hg15@aub.edu.lb \\ Muhammad H. Zaman \\ Departments of Biomedical Engineering and International Health \\ Boston University \\ Boston, MA 02215 \\ zaman@bu.edu \\ Youseph Yazdi \\ Center for Bioengineering Innovation and Design \\ Johns Hopkins University \\ Baltimore, MD 21218 \\ yyazdi@jhu.edu
}

* I. Elhajj is the corresponding author 
Abstract - The study introduces and evaluates a unique inter-faculty service learning course as a pedagogical model that enhances students' learning and knowledge of health problems and associated engineering intervention design for populations affected by protracted crises. A protracted crisis is defined as a situation affecting the basic needs of a large population for an extended or unexpected period of time. ${ }^{1}$

Background: With an increase in humanitarian protracted crises around the world, due to conflict and natural disasters, we are in need to reinvent how we educate, train, and conduct research in these environments. Engineering and Health Sciences disciplines, individually and collectively, have been working to fill the gaps and address pressing public health issues. However, courses merging those disciplines and focusing on emerging humanitarian challenges have been limited. To meet this need, and to expose the complexity of refugee health and well-being, the Humanitarian Engineering course "Design of Engineering Solutions for Health Challenges in Crisis" was launched in July 2017.

Intended outcomes: The contribution is a set of elements that can serve as a foundation for developing an inter-faculty service learning course model through which students of any major acquire skills in design thinking, interdisciplinary approaches, and contextualized innovation to create practical solutions that impact populations in need.

Application design: Through a literature review and an iterative course development process, the different components of the course model were developed and assessed to ensure students accomplished learning outcomes and professional skills.

Findings: The study recommends a set of five elements that could be used as a foundation for developing an inter-faculty service learning model. Those include modular learning, intermittent session types, participatory active learning, intensive learning, and teamwork.

Index Terms - Blended learning, design thinking, humanitarian engineering, service learning, team based learning, multidisciplinary, professional skills.

\section{INTRODUCTION}

Although engineering education has made strides in the past several decades, it still falls short from achieving much needed reforms. In fact, the gap between education and practice, although a recurrent theme across disciplines, has been heavily highlighted in the engineering field..$^{2-4}$ Moreover, engineering courses are using teaching methods that dissociate between lectures and labs and therefore do not engage students. ${ }^{4}$ Additionally, Smith et al. ${ }^{5}$ show that engineering students generally don't incorporate social factors into consideration when designing engineering solutions.

On the other hand, health sciences have been shown to lack quantitative tools, and life sciences such as biology do not include interdisciplinary approaches. ${ }^{6}$ Moreover, health education often does not prepare students to adapt and take account of cultural and social contexts. ${ }^{7-9}$

According to Latimer et al. ${ }^{6}$, engineers have been increasingly interested in tackling issues pertaining to health sciences and improving human health. This is translated by the growth of fields such as biomedical engineering. The collaboration between health sciences and engineering is mutually beneficial as it allows concrete applications of engineering concepts and tools in qualitative fields ${ }^{6}$ by, for example: promoting human-centered engineering, and finding tools to 
International Journal for Service Learning in Engineering, Humanitarian Engineering and Social Entrepreneurship Vol. 14, No. 2, pp. 16-32, Fall 2019

ISSN 1555-9033

support and enhance response to public health needs.

The collaboration between both fields is especially relevant in tackling current and emerging humanitarian issues. Humanitarian engineering is an emerging discipline that started to be established in the early 2000 s across the world. ${ }^{5,10,11}$ This relatively new discipline aims at utilizing scientific methods and principles to enhance the quality of life and well-being of disadvantaged populations through simple, sustainable, and inexpensive solutions. ${ }^{12-14}$ Humanitarian engineering encompasses multidisciplinary comprehensive projects addressing a variety of issues affecting the basic needs of human beings ${ }^{11,12}$, in both protracted and emergency crises. ${ }^{13}$ To do so, humanitarian engineering informs the technical aspect of engineering with socio-political, economic, and global factors, making it "a balance of technical excellence, economic feasibility, ethical maturity, and cultural sensitivity". ${ }^{11}$ According to Vandersteen ${ }^{15}$, four criteria distinguish humanitarian engineering from conventional engineering work. First, it helps solve a need in a certain population; second, it addresses a basic human need; third, projects are elaborated with beneficiaries; fourth, it uses engineering and technical skills to answer identified needs. ${ }^{15}$ As conflicts and natural disasters have increased humanitarian protracted crises around the world, engineers ought to be better prepared to address global challenges. Addressing humanitarian challenges requires a combination of disciplines, cultures, academia, and multi-sectoral approach. ${ }^{16}$ In fact, humanitarian engineering emerged as a development of "Systems Engineering" principles that had not been very successful at addressing humanitarian issues. ${ }^{11}$

Humanitarian engineering curricula bring together faculty members and students from engineering and social science disciplines. ${ }^{11}$ This multi-disciplinary approach has been shown to allow engineering students, among others, to understand how to better integrate social sciences into their profession. ${ }^{5,10}$ The programs have been successful at developing students' professional and personal skills, such as multi-disciplinary and cross-cultural competencies and teamwork. ${ }^{17,18}$ After completing humanitarian engineering courses, students believe to have improved their communication and conflict-resolution skills, impacted the lives of people, and "become better people". ${ }^{18}$

Given the local proximity of the refugee health challenge in Lebanon and the desire to develop new ideas, discourse and solutions, the Faculty of Health Sciences and the Maroun Semaan Faculty of Engineering and Architecture at the American University of Beirut, in collaboration with Boston University and Johns Hopkins University, launched in July 2017 a new interdisciplinary service learning course entitled "Design of Engineering Solutions for Health Challenges in Crisis". The collaboration between the authors was conceptualized at a workshop at AUB. The course was developed in response to an identified gap in health and humanitarian oriented interdisciplinary course offerings. The goal of this effort is to encourage students to engage in designing engineering solutions that would alleviate health challenges faced by people in protracted humanitarian crises. During the past two years, four sessions were offered and feedback from students and faculty was gathered to evaluate their experiences and learning outcomes.

This paper aims to detail the inter-faculty (instructors and mentors from Engineering, Public Health, Business, Social Sciences) service learning course model developed and to assess its effectiveness in terms of student learning and knowledge gain. The model developed is shown to help enhance students' learning and knowledge of health problems and associated intervention design, for populations affected by protracted crises, through a participatory, immersive and active learning approach that promotes student engagement. The model was evaluated for both process and impact using direct and indirect assessment methods that measure students' personal and 
International Journal for Service Learning in Engineering, Humanitarian Engineering and Social Entrepreneurship

Vol. 14, No. 2, pp. 16-32, Fall 2019

ISSN 1555-9033

professional gains as well as their satisfaction with the experience. Lessons learned from those experiences helped set foundations for an inter-faculty service learning course model that can locally and internationally inform inter-faculty collaborations, teaching methodologies, and interactions between academia and local communities affected by humanitarian crises.

The next section of this paper will discuss the need for a health-focused humanitarian engineering course. The third section of this paper will discuss the methodology followed in this study. The paper then moves on to elaborate on the model development and the current model form. The penultimate section will describe the results of the evaluation conducted to assess the efficacy of this model on student learning, knowledge gain, and skills gain. The last section will summarize the findings and give recommendations to further enhance the model proposed.

\section{The NeEd for a Health-Focused Humanitarian EngINeERING Course}

To date, humanitarian engineering has been offered across universities in the form of minors, specializations, courses, programs, or extracurricular centers. While health issues are mentioned and studied in some of the programs, they are only one of many other basic needs explored. In a review of a dozen humanitarian engineering initiatives, given by universities such as the University of New South Wales, RMIT University, Penn State University, The Ohio State University, and the University of Colorado Boulder, none seems to offer a course that is given in collaboration between public health and engineering faculty, and that simultaneously teaches students how to conduct health-related needs assessments and develop engineering designs. Particularly in the setting of protracted crises, addressing basic needs does not ensure the long-term wellbeing and health of populations hence the importance of tackling public health issues in humanitarian interventions.

Faculty members at the American University of Beirut, Boston University and Johns Hopkins University worked together to develop first a concept note, and then a course that addresses this thematic gap. In order to develop a course model that merges the disciplines of public health and engineering, the educational strengths and shortcomings of the two disciplines had to be considered both independently and when combined into humanitarian engineering courses.

The Accreditation Board for Engineering and Technology (ABET) requires engineering programs to have the following student outcomes (Criteria for Accrediting Engineering Programs - General Criterion 3) in order to be accredited: designing within constraints and context (including social, economic, environmental), being more aware of current issues and the impact of engineering, identifying and solving problems, communicating effectively with diverse audiences, and functioning in multidisciplinary teams. ${ }^{19}$ While engineers excel in the technical field (designing, identifying, and resolving problems), they often face difficulties with communication skills, data collection and brainstorming ideas. ${ }^{2}$ Soft skills, such as interpersonal skills and working in the field with multidisciplinary teams, are often neglected in academia although heavily emphasized in the professional world. ${ }^{3,20}$ The shortcomings of engineering education are most apparent in entry-level engineering positions. ${ }^{2}$

On the other hand, health science education has limited interdisciplinary interactions but it incorporates quantitative tools in curricula. ${ }^{7}$ Social science education can also increase inclusion of local communities to tack issues pertaining to social justice. ${ }^{21}$

Attributes from engineering and health science students complement each other; yet, curricula that have previously incorporated both engineers and social sciences under the theme of humanitarian engineering have faced several challenges. They have often given more attention to 
International Journal for Service Learning in Engineering, Humanitarian Engineering and Social Entrepreneurship

Vol. 14, No. 2, pp. 16-32, Fall 2019

ISSN 1555-9033

technology than other components. Students engaged in such courses have found it difficult to reach a balance in teamwork whereby all teammates regardless of their background are equally valued (engineering vs social sciences). ${ }^{7,10}$ Moreover, since service learning provides students with the opportunity to collaborate with partners on projects with previously identified needs ${ }^{3}$, it often lacks the needs assessment skills student could benefit from acquiring in the field.

In his suggested guideline for building a humanitarian engineering education, Ba-Aoum recommends the use of problem-based and project-based learning methods to enhance teamwork and to promote new ways of thinking in order to define and resolve problems. ${ }^{10}$ Project based learning also increases student engagement and assimilation. ${ }^{22}$ Problem-oriented and project-based learning (POPBL) promote an integrated education that is "interdisciplinary, contextualized, student-centered, based on a complex understanding of technological knowledge", and that contributes to bridging society and academia. ${ }^{23}$ Service learning allows students to apply the theoretical knowledge they have gained through their curriculum in an immersive and motivational manner, and reinforces a sense of civic responsibility and community engagement. ${ }^{5,14}$ Service learning courses, that are project-based, foster cultural competency and promote skills such as: critical thinking, problem-solving, project management, creativity, teamwork, communication, and leadership. ${ }^{18,23}$ The aim of this service learning model is to create teams of participants from engineering, health science, social sciences, business, etc. who equally contribute to the proper evaluation of a problem or need and the design of a practical and successful solution.

Bearing all of the above in mind, a novel course format, that departs from traditional models and that addresses both academic and professional needs, was developed. In fact, in addition to attending lectures, students in the course are required to perform professional activities throughout the course such as report writing, pitching, and teamwork in order to further develop soft skills. Moreover, students work in teams and carry out fieldwork throughout the course to increase engagement. The final course model offers a service learning, problem oriented and project based experience in an intensive timeframe. It consequently aims to foster skills such as teamwork, communication, brainstorming, context awareness, problem solving, and balanced multidisciplinary work.

\section{MethodOLOGY}

In order to develop and refine the inter-faculty service learning course model, surveys were administered to students from all four offerings of the course, and interviews were held with mentors. Mentors are public health and engineering faculty members who are assigned to be reference points for the teams. Each team is assigned a mentor from each field to advise them throughout the course.

\section{A. Students of session 1: Summer 2017}

Students from the summer 2017 session were asked to fill out an end-of-course self-administered, without the involvement of the data collector, satisfaction survey which consisted of 9 scale questions, and 3 open ended questions. The questions assessed students' satisfaction with the course's structure, sessions, lecturers, and modules. 34 students completed the survey, and those included public health and engineering professionals (practitioners from NGOs), as well as undergraduate and graduate engineering and public health students. 
International Journal for Service Learning in Engineering, Humanitarian Engineering and Social Entrepreneurship

Vol. 14, No. 2, pp. 16-32, Fall 2019

ISSN 1555-9033

\section{B. Students of session 2: Winter 2018}

The satisfaction survey used in the previous session was further developed to contain 18 scale questions and 3 open ended questions that helped further understand students' satisfaction with their learning experience. Components that were assessed included new course modules, activities, hackathon and structure. The survey was filled out by 17 students.

Moreover, as an improvement over the previous session, students were asked to fill out selfadministered beginning and end-of-course surveys consisting of 15 scale questions. The surveys allowed for the analysis of students' knowledge gain. In fact, surveys probed students on their perceived self-efficacy in terms of understanding of health problems and associated design interventions in the context of protracted humanitarian crises. Assessments using self-efficacy help identify patterns and therefore can be used as guidelines in developing programs that aim to meet specific skills and competencies. ${ }^{6,24,25}$ Surveys were filled by students at the American University of Beirut. The pre-course survey was completed by 20 participants, and the post-course survey was completed by 18 participants.

\section{Students of sessions 3 \& 4: Summer 2018 and Winter 2019}

In the last two offerings of the course, more comprehensive tools were developed to assess both students' learning and knowledge gain. This was done through both direct and indirect assessment methods. The course satisfaction and knowledge gain surveys administered in the previous session were further developed, assignments were administered and graded, and interviews were held with mentors.

\section{1) Self-administered surveys:}

Students' knowledge gain was assessed through self-administered beginning and end-of-course surveys that allowed for an analysis of students' change in understanding of health problems and associated design interventions in the context of protracted humanitarian crises. The knowledge gain surveys were based on the ones used in previous sessions but were further developed to include 16 scale questions, 2 demographics questions, and 1 open ended question. Students were asked to write a randomly selected code on both the beginning and end of course surveys to compare individual progress. 15 students from the Summer 2018 session and 28 from the Winter 2019 session filled out both surveys.

Moreover, students' satisfaction with the course process and their perception of benefits were assessed through a self-administered survey distributed at the end of the course. Benefit variables assessed include critical thinking, contextualized intervention design, problem-solving, tolerance of diversity, teamwork, and multidisciplinary competencies. The evaluation survey was based on the ones used in previous sessions but was further developed to include 32 scale questions and 5 open ended questions. 15 students from the Summer 2018 session and 37 from the Winter 2019 session filled the survey.

\section{2) Direct Assessment of Student Performance:}

Throughout the course, as well as at the end of each module, the performance of course participants was assessed through the following assignments, which were linked to the course learning outcomes and assessed using rubrics (see Table I): 
International Journal for Service Learning in Engineering, Humanitarian Engineering and Social Entrepreneurship

Vol. 14, No. 2, pp. 16-32, Fall 2019

ISSN 1555-9033

Problem Definition (15\%): This assignment directly measured students' ability to conduct in teams a needs assessment as well as identify and define a problem to tackle in a humanitarian setting. After conducting a needs assessment based on the fieldwork, students were asked to submit a problem statement clearly defining the targeted population, context, and motivation, as well as a list of needs specifications covering at least four different aspects. Students received feedback on this assignment from their public health mentors, and the course coordinators. Scores were assigned equally between the problem statement and needs specification based on the levels of accomplishment: Exemplary, Satisfactory, Developing and Unsatisfactory.

Design assignment (20\%): Each team proposed a design solution that addresses the public health problem they identified. Students were assessed on how appropriate their approach was to solving the problem; the inclusion of clear, detailed, and specific justification grounded in theory/scientific methods; the consideration, analysis and comparison of numerous alternatives; and the inclusion of a step by step work plan, with tasks allocated by team member, and resources needed. Students received feedback on their prototype from both the engineering mentors and course coordinators.

Prototype (30\%): Each team developed a prototype of the proposed solution. The prototypes were evaluated in terms of the appropriateness of technologies used and usability, which translated into three criteria: prototype completeness, testing execution, and complexity/effort. The course coordinators assessed the prototypes during students' final presentations.

Teamwork (10\%): To gather an internal feedback and better prepare students for the self and peer evaluations commonly requested in professional settings ${ }^{20}$, students were asked to individually submit peer evaluations assessing their own contribution and that of their team members. Teamwork performance was then graded by faculty members according to each student's team members' input.

Final Presentation (20\%): Each team worked on, polished, and then finally pitched their solution to a jury on the final day of the course. The jury was composed of four professionals from the fields of engineering, humanitarian interventions, entrepreneurship, and public health. Students were evaluated on the following criteria: motivation and the need selection, impact and significance of problem addressed, design process followed and fit of proposed solution, creativity and originality, prototype quality, sustainability of solutions, feasibility and potential impact of the solution, and presentation and teamwork. Scores were assigned from 1-5 points (low or limited results) and 6-10 points (positive and significant results) for each of the criterion. The average of the scores of all four judges was computed to get an assessment of each team's work.

Blog Post (5\%): Each student submitted after the end of the course a short reflective blog post describing their experience. This blog post was graded by the course coordinators based on the following criteria: awareness of the event, understanding of the context, critical thinking, applying what was learned in class, responsibility to the community, and impact on the student.

\section{3) Interviews:}

Two months after the end of the Summer 2018 course, public health and engineering course mentors were asked to participate in one-on-one interviews aiming to gather their feedback in terms of the course format and structure, their perceived benefit of the course to students, and the barriers and facilitators to their involvement in the course. Two mentors attended, including one engineer and one public health specialist. 
International Journal for Service Learning in Engineering, Humanitarian Engineering and Social Entrepreneurship

Vol. 14, No. 2, pp. 16-32, Fall 2019

ISSN 1555-9033

\section{An InTer-Faculty Service Learning Course Model}

The developed course aims to challenge students to identify health needs faced by populations in protracted crises and create solutions addressing those needs. The protracted crisis studied in the context of this course was the Syrian refugee crisis in Lebanon. The service learning component of the course required students to directly work with Syrian refugees living in informal tented settlements in the Bekaa Valley of Lebanon to understand their needs and create solutions that they can utilize. The contact with refugees was made through a local organization working with refugees on a daily basis. Field visits and material expenses were covered by the course.

The current course model was developed over four sessions. An iterative process was followed to devise the final version of the model. Therefore, the course evolved with each of the three offerings. However, the organizing team and group division were recurrent across all sessions.

The course was developed and organized by two electrical and computer engineering professors and two public health faculty members at the American University of Beirut, in collaboration with a professor in biomedical engineering at Boston University and another professor from Johns Hopkins University. All six professors gave lectures throughout the course, in addition to guest speakers including professionals, researchers, and faculty members. Moreover, faculty members from the Faculty of Health Sciences and the Maroun Semaan Faculty of Engineering and Architecture mentor students throughout the course in the development of their needs assessment tools, identification of problem to tackle, design process, prototyping, and pitching. A project coordinator is also available to support students during field visits and help them secure needed equipment for prototyping.

In all sessions, teams were formed by the organizers on the first day of class. The groups were made to maximize diversity of nationality, experience, background, major, class level, language proficiency and gender. Grouping students of different majors together creates a dynamic of complementarity and mutual aid in order to achieve a common goal, which enhances learning. 3,26,27 Teamwork also contributes to students' engagement and positive perception of classes. ${ }^{26}$ Therefore, significant emphasis is placed on teamwork during this course.

\section{A. Session 1: Summer 2017}

The first iteration of the course was given over the span of 3 days from July 6 to 8, 2017 at the American University of Beirut. ${ }^{28}$ The course was divided into two main parts: 1.5 days were spent in class sessions during which 11 lecturers delivered 6 presentations covering the course material. The remaining 1.5 days translated into an engineering hackathon, where students brainstormed ideas, designed solutions and created prototypes in an accelerated timeframe, that culminated in a competition. Although $82 \%$ of students rated the course good or excellent and $97 \%$ agreed to the statement that they "would participate in other similar events if the topic is relevant", $35 \%$ of students thought they weren't given enough time to generate a concept, and $25 \%$ recommended to increase the duration of the course altogether. Feedback from this first session was gathered and taken into consideration in the development of the second iteration of the course. Some of the feedback included increasing the course duration, gaining more contextual insight, and having the possibility to interact with faculty members from more diverse backgrounds. ${ }^{29}$ 
International Journal for Service Learning in Engineering, Humanitarian Engineering and Social Entrepreneurship Vol. 14, No. 2, pp. 16-32, Fall 2019

ISSN 1555-9033

\section{B. Session 2: Winter 2018}

The second session of the course took place over the span of three weeks from January 8 to 26, 2018. ${ }^{30}$ The course was given simultaneously on two campuses: Johns Hopkins University in Baltimore and the American University of Beirut in Lebanon. 12 lectures were given on the American University of Beirut Campus and recorded to be watched by students in Baltimore. Teams were composed of participants from both campuses, and therefore had to work together remotely throughout the course despite the time difference to produce the various course deliverables. To this effect a virtual interface was established connecting both campuses. In this session, all lectures were condensed in the first week of the course, and in the remaining two weeks students worked under the guidance of their engineering and public health mentors to develop needs assessment tools, conduct fieldwork, identify their problems, design a solution, prototype it, and pitch their projects. Students at JHU did not participate in the field work directly but were regularly updated by their teammates in Lebanon. Mentors were assigned to students based on their field of interest and students were responsible for setting up meetings with them, as they saw fit. $47 \%$ of students thought the course was good, while $53 \%$ found it to be excellent. $100 \%$ of students had a positive experience and would recommend the course to others. Moreover, as an improvement from the previous course, $100 \%$ of students agreed they had sufficient time to generate their concept. However, $18 \%$ students complained about working remotely with students in Baltimore. In fact, although students in Beirut liked collaborating with students from the USA, they recommended having international students come attend the course in person for a more comprehensive experience. In addition, up to $18 \%$ of students perceived mentorship to be insufficient and 12\% felt the fieldwork was not well organized, even though $94 \%$ found it to be motivating and personally enriching.

\section{Sessions 3 \& 4: Summer 2018 \& Winter 2019}

The Summer 2018 session of the course was offered over the span of three weeks as well, from the $2^{\text {nd }}$ to the $20^{\text {th }}$ of July 2018. The Winter 2019 session was from the $2^{\text {nd }}$ to the $18^{\text {th }}$ of January 2019. The courses were based on the model of the second session, but included some improvement. In fact, these sessions were based on a course format that merges theory and practice. This application breaks down traditional demarcation between knowledge and practice and facilitates learning by way of concepts learned being directly applied as part of a developing project. ${ }^{31}$ The modules were as follows: understanding the context of the Syrian refugee protracted crisis, conduct a needs assessments and identifying problems, creating an engineering design that answers the problem, prototyping a solution, and pitching it to a jury. Therefore, during the Summer 2018 session the 17 course lectures were intermittently given with 4 field visits, 8 mentoring sessions, and 15 teamwork sessions in between allowing for the direct application of concepts learned during lectures (Table I). Lectures (Summer 2018 list Table II) were delivered by 19 speakers, including 3 practitioners, 9 engineering professors from the American University of Beirut (AUB), Boston University (BU), and Johns Hopkins University (JHU), and 4 public health and social sciences professors from AUB and BU. However, during the Winter 2019 session, students were only able to conduct two field visits due to the harsh weather conditions and the bad circumstances faced by refugees at that time caused by flooding. This in itself was a learning experience for students to 
highlight the realities on the ground and the challenges of field work. Lectures were delivered by 5 engineering professors from AUB and BU and by 5 public health and social science professors from AUB and BU. Each of the four different scheduled field visits served a purpose. During Summer 2018, the first one served to introduce students to the community partner and context. During the second visit, students conducted a needs assessment. After reviewing the gathered data with mentors, students went back for a third visit to gather more refined information. Finally, students had to go to the field after having developed their prototypes to discuss the feasibility and acceptability of their solutions with the community. Mentoring sessions were set and defined in the schedule to ensure students were better guided and supported. Separately, course participants were expected to commit themselves on a full-time basis for the duration of the course. This intensive teaching technique allowed students to be fully immersed in the case, to form more interactive teams, and to get a real feel of practical interventions. ${ }^{5}$ Based on previous session feedback, international students were required to attend the course in person, which led $9 \mathrm{BU}$, and one student from Norwegian Technical University (NTNU, Trondheim) to travel to Beirut for the duration of the Summer 2018 session. As for the Winter 2019 session, 12 BU students traveled to Beirut for the duration of the course. In addition, as the course was approved as a general education social sciences course for undergraduates from all majors, as well as a technical elective for engineering and public health students at the AUB, formal assignments were developed to monitor students' assimilation of the course material and achievement of learning outcomes. As a result, from both sessions, at least $90 \%$ were satisfied with the course and would recommend to have more inter-faculty service learning courses. More than $80 \%$ of students found the feedback they got on their assignments to be useful for their project's development, found the mentorship to be sufficient and beneficial, and believed they were provided enough support. Moreover, at least $92 \%$ of students would recommend the course to others. However, $27 \%$ of students from the Summer 2018 session and 29\% from the Winter 2019 session believed the time needed to develop a concept was not enough, and a few students requested to have an additional field visit. 
International Journal for Service Learning in Engineering,

Humanitarian Engineering and Social Entrepreneurship

Vol. 14, No. 2, pp. 16-32, Fall 2019

ISSN 1555-9033

\section{TABLE I}

SCHEDUle of FinAl COURSE MOdEL FOR THE WINTER 2019 COURSE INCLUDING MODULES, LEARNING OUTCOMES AND ASSIGNMENTS

\begin{tabular}{|c|c|c|c|c|}
\hline Day & Module & Session type & $\begin{array}{l}\text { Learning } \\
\text { outcome }^{1}\end{array}$ & Deliverables \\
\hline 1 & $\begin{array}{l}\text { Understanding the refugees' context and public health } \\
\text { challenges faced in humanitarian setting }\end{array}$ & 5 Lectures & 1 & \\
\hline 2 & \multirow{6}{*}{$\begin{array}{l}\text { Conducting a needs assessment and developing a problem } \\
\text { statement }\end{array}$} & Field visit & 2 & \\
\hline 3 & & 2 Lectures, 1 Mentoring, & 1,2 & \\
\hline & & Teamwork & & \\
\hline 4 & & 2 Mentoring, Teamwork & 1,6 & \\
\hline 5 & & Fieldwork, Teamwork & 1,2 & \\
\hline \multirow{2}{*}{6} & & 1 Mentoring, Teamwork & 1,6 & \\
\hline & Creating an engineering design for humanitarian contexts & 3 Lectures, 1 Mentoring & 3,4 & \\
\hline 7 & $\begin{array}{l}\text { Conducting a needs assessment and developing a problem } \\
\text { statement }\end{array}$ & Fieldwork, Teamwork & 2,3 & Problem statement \\
\hline $\begin{array}{l}8 \\
9\end{array}$ & Creating an engineering design for humanitarian contexts & $\begin{array}{l}3 \text { Lectures, Lab tour, } 1 \text { Mentoring } \\
1 \text { Mentoring, Teamwork }\end{array}$ & $\begin{array}{l}1,3,4 \\
3,4,6\end{array}$ & Design solution \\
\hline $\begin{array}{l}10 \\
11\end{array}$ & $\begin{array}{l}\text { Prototyping: from design to effective, feasible, and } \\
\text { sustainable solution }\end{array}$ & $\begin{array}{l}1 \text { Mentoring, Teamwork } \\
\text { Fieldwork, Teamwork }\end{array}$ & $\begin{array}{l}2,3 \\
3,4,6\end{array}$ & \\
\hline 12 & \multirow{2}{*}{ Pitching a project } & $\begin{array}{l}2 \text { Lectures, } 1 \text { Mentoring, } \\
\text { Teamwork }\end{array}$ & $3,5,6$ & \\
\hline 13 & & Teamwork, Final jury & 5 & Prototype; Final Pitch \\
\hline \multicolumn{2}{|l|}{$\begin{array}{l}\text { Post } \\
\text { course }\end{array}$} & & & $\begin{array}{l}\text { Blog post } \\
\text { Teamwork review }\end{array}$ \\
\hline \multicolumn{5}{|c|}{$\begin{array}{l}\text { ctive communication tools to promote the solution to a } \\
\text { ectively in a team with diverse backgrounds and persp }\end{array}$} \\
\hline
\end{tabular}

TABLE II

LeCTURES Given THROUGHOUt THE SUMmer 2018 COURSE

\begin{tabular}{|c|c|c|}
\hline Day & Lecture & Type \\
\hline \multirow{5}{*}{1} & $\begin{array}{l}\text { Demographics, region, and history of the refugee population and socio-economic challenges faced by various } \\
\text { waves of refugees in Lebanon }\end{array}$ & Public Health \\
\hline & No Place for a Baby: Gendered Violence, Stateless Children, and the Place of Trauma & Social Sciences \\
\hline & The current challenges in health in humanitarian context & Public Health \\
\hline & Introduction to SPHERE and context assessment tools: infrastructure, social, geographic, environmental, shelter & Public Health \\
\hline & Respect, sensitivity, cultural understanding and ethical conduct of research & Ethics \\
\hline \multirow[t]{2}{*}{3} & $\begin{array}{l}\text { The cycle of participatory intervention design with particular focus on assessment. Hands-on activities on some } \\
\text { tools used in humanitarian settings. }\end{array}$ & Public Health \\
\hline & Problem statement formulation & Engineering \\
\hline \multirow[b]{2}{*}{6} & What is design? Examples of good and bad design. What makes a design particularly good? & Engineering \\
\hline & $\begin{array}{l}\text { Design Thinking. The process of creating innovations. Steps, processes and common issues. Hands-on basic } \\
\text { design activities. }\end{array}$ & Engineering \\
\hline \multirow{3}{*}{8} & Feedback on problem statement and refinement & $\begin{array}{l}\text { Public Health }+ \\
\text { Engineering }\end{array}$ \\
\hline & Technologies for developing humanitarian health solutions. & Engineering \\
\hline & Case studies on engineering solutions for humanitarian health and refugee support. & Engineering \\
\hline \multirow{2}{*}{10} & A systems level understanding of health - who are the stakeholders and where do we go from here? & Public Health \\
\hline & Understanding feasibility and creating scale and sustainability of solutions, both in impact and in finances. & NGO presentations \\
\hline 12 & Students hands-on critique of humanitarian engineering interventions & Engineering \\
\hline \multirow{2}{*}{15} & How to Pitch? & Entrepreneurship \\
\hline & Innovation \& entrepreneurship & Entrepreneurship \\
\hline
\end{tabular}


ISSN 1555-9033

\begin{abstract}
Assessment Results
The iterative course development process has resulted in an inter-faculty service learning course model with high participant satisfaction. The model was evaluated in terms of structure as well as against both knowledge and skill gain. This section will detail the strengths and weaknesses of the model developed and assessed in sessions 3 and 4.

Both the indirect and direct assessment performed in terms of the course objectives and learning outcomes have shown that students were able to successfully achieve the course learning outcomes.
\end{abstract}

\title{
A. Indirect Assessment Results
}

The results presented in Figure I show the percentage of students having agreed or disagreed to benefit statements presented to them at the end of the course. On the other hand, Figure II shows a comparison of students' perception of knowledge before and after having taken the course.

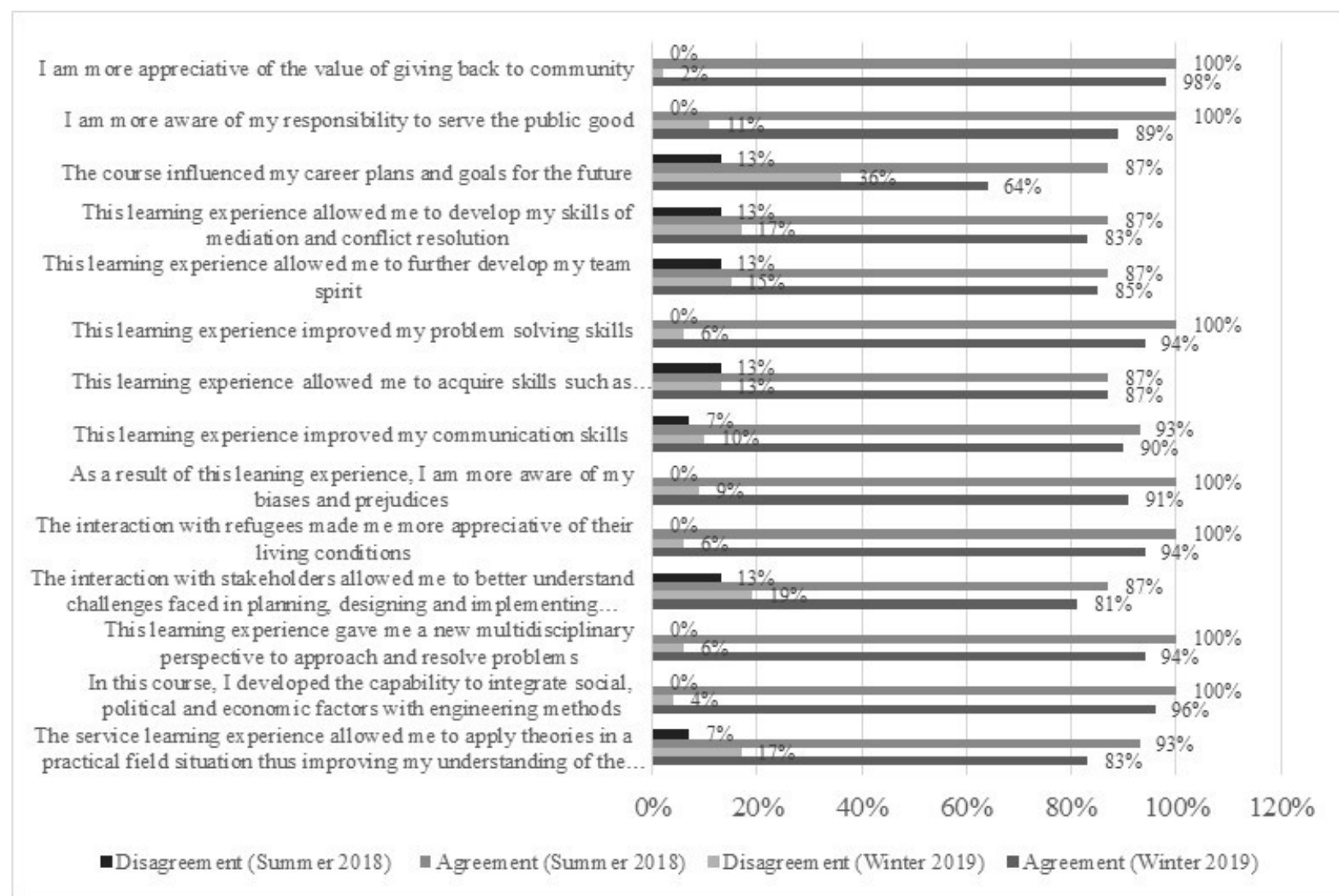

FIGURE I. Student's ResPonse to PERCEPTION OF BENEFITs Gained Post CoURSE (SESSIONS 3 \& 4: SUMMER 2018 AND WINTER 2019)

In terms of course structure and delivery, students generally identified the following components as contributors to their acquisition of new skills or development of existing ones: service learning (including fieldwork), multidisciplinary work, mentoring, and teamwork. In fact, students not only agreed to the fact that the fieldwork was motivating and personally enriching, 


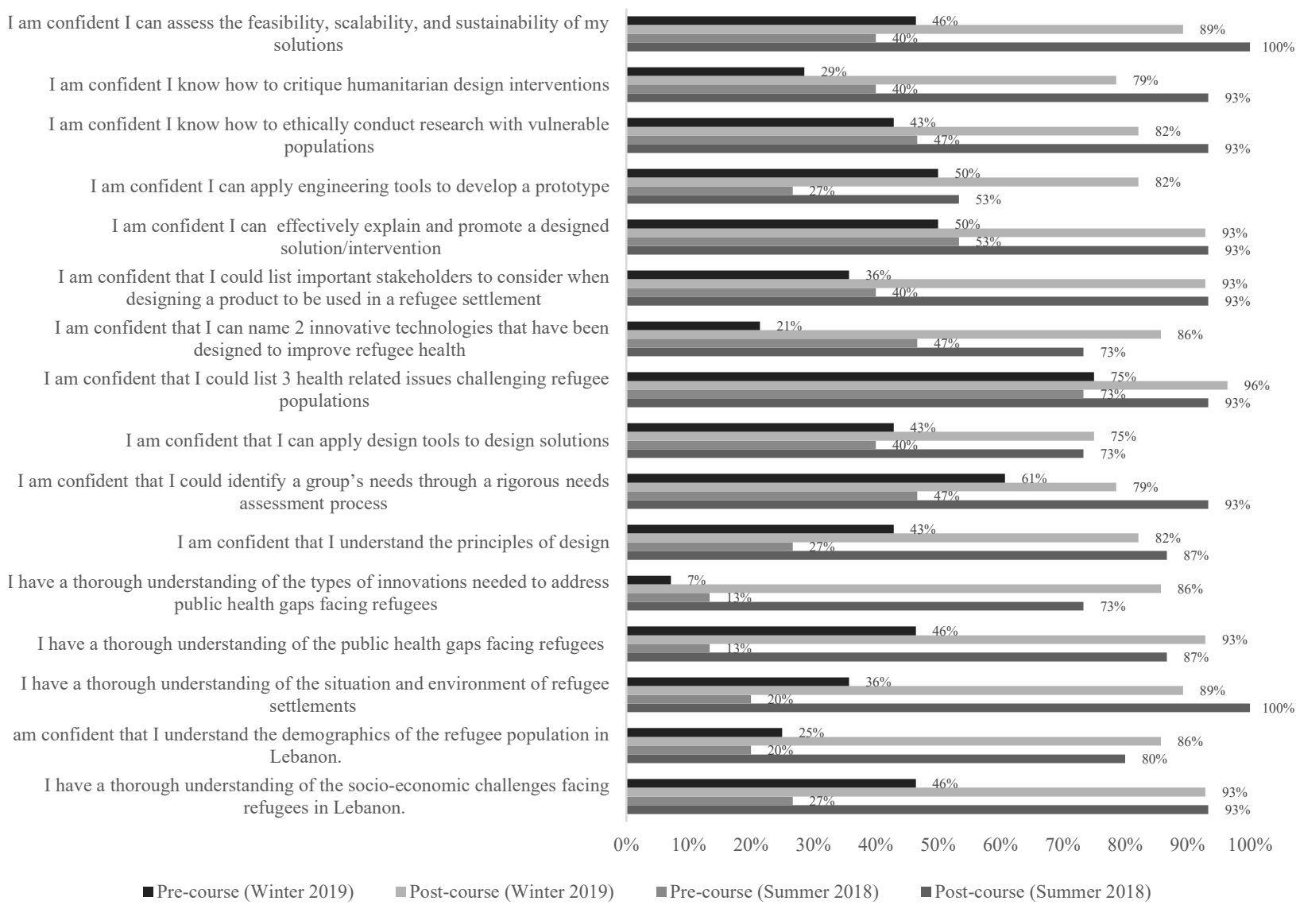

FIGURE II. Students’ Perception of KNOWledge Gain Through Course

(SESSIONS 3 \& 4: SUMMER 2018 AND WINTER 2019)

but they also emphasized it as core component of the learning process. Indeed, 93\% of Summer 2018 enrolled students and $83 \%$ of the Winter 2019 students felt the service learning experience allowed them to improve their understanding of theoretical concepts (Figure I). The multidisciplinary approach allowed students to tackle problem identification and problem solving in what they perceived to be a novel way. This approach was praised by students in terms of lectures, mentorship, and teamwork. Moreover, students felt that the mentorship sessions allowed them to approach their tasks more critically and therefore be more efficient. Generally, the majority of students were in agreement that they had a positive experience working in multi-disciplinary teams. On the other hand, students identified, in open-ended questions, time to be an issue in terms of validating a problem and generating a concept for a design solution. In addition, students of the Summer 2018 session found remote lectures (given through videoconferencing) hard to follow. No remote lectures were given in the Winter 2019 session.

In terms of perceived knowledge gain, by the end of the course, all students of the Summer 2018 session and $89 \%$ of the Winter 2019 reported having a thorough understanding of the humanitarian context studied (Figure II). In fact, the percentage increase in students' understanding of the demographics and socio-economic challenges facing refugees in Lebanon was at least twice as high in the Summer 2018 session than in the Winter 2019 session. In addition, at least $70 \%$ of the Summer 2018 and Winter 2019 students reported to have gained through this 
course an understanding of both the public health gaps facing refugees and the types of innovations needed to address those gaps. More than $73 \%$ of students of both sessions agreed that after taking this course they were able to apply design tools to design solutions and 93\% of the Summer 2018 and $82 \%$ of the Winter 2019 students agreed that they were confident to ethically conduct research with vulnerable populations, perform a stakeholder analysis when designing a product to be used in a refugee context, and pitch and promote the designed product.

As for perceived skills gain, by the end of the course, students' perception of gain was noted in a variety of skills (Figure I) pertaining to design thinking, interdisciplinary approaches, and contextualized innovation. In fact, more than $90 \%$ of the Summer 2018 and Winter 2019 students agree that the course helped improve their problem-solving skills, at least $90 \%$ agree they have improved their communication skills, and $87 \%$ gained skills such as time management, critical thinking, planning, teamwork, mediation, and conflict resolution.

\section{B. Direct Assessment Results}

Each skill in the rubrics was assessed over four levels of accomplishment (exemplary, satisfactory, developing, and unsatisfactory). If the student's group scored in the top 2 levels the skill is considered accomplished. Based on this assessment $85 \%$ of the Summer 2018, and Winter 2019 students were capable of appropriately approaching a problem with a detailed and specific intervention design including a step-by-step work plan, resource allocation for the development of the design, and the consideration and comparison of numerous design alternatives. Moreover, $100 \%$ of students of both sessions were able to develop a context, population, and motivation specific problem statement which is clearly defined without hinting at a solution. However, only $66 \%$ of the Summer 2018, and 85\% of the Winter 2019 students accomplished the skill of developing comprehensive and relevant needs specifications for their problem statement covering several aspects (such as technical, legal, social, and sustainability).

Each skill demonstrated in the students' final presentations was assessed using a rubric over 2 levels of accomplishment. If the group scored at the top level, the skill is considered accomplished. The percentages reported are the overall percent accomplished score given to all teams of the Summer 2018 and Winter 2019 session, by all judges for each skill. For instance, 96\% of external judges' rubric scores showed students' accomplishment of the skills of carrying out a needs assessment process and developing a need statement, 91\% for the skill of selecting a significant problem with broad impact, and $66 \%$ for following a clear design process devising a solution that answers the identified need and need specifications. However, only $62 \%$ of judges' scores indicated students accomplished the skill of proposing solutions that have major elements that are unique and innovative, and $77 \%$ indicated students achieved the skills of creating sustainable solutions and performing a convincing feasibility assessment of that solution. The students can propose solutions that conserve resources, advance the overall efficiency with a positive outcome to the community, and are highly likely to address the needs effectively. On the other hand, 74\% of judges' scores indicated students accomplished the skill of developing relatively advanced prototypes given time constraints and $83 \%$ the skill of pitching a project and working in a team. It is worth noting that the results of the Summer 2018 session are based on 4 judges that evaluated 3 teams with 5 students per team. As for the Winter 2019 session, 5 judges evaluated 7 teams, each team with 6 to 7 students. 


\section{Feedback from Mentors}

Separately, feedback from both an engineering mentor and a public health mentor was gathered in relation to the course format, facilitators and barriers to mentoring, and perceived benefit to students. Both mentors highlighted that students benefitted from working in multi-disciplinary teams and getting to experience field work. These course elements allowed students to learn from each other and gain a new insightful perspective. Mentors felt that they had an added-value to students throughout the course by providing them with guidance and feedback, helping them filter their ideas, keeping them grounded, realistic and aware of time constraints, and developing with them an action plan. The public health and engineering mentors had different experiences with students in terms of methodological and technical skills. While the public health mentor felt students gained those skills through lectures and field work, the engineering mentor felt students displayed limitations in terms of design approach. He noted that students had a hard time connecting what was taught in lectures with the actual application. He believes this is due to a lack of design experience as this skill comes with time. Consequently, mentors had conflicting points of view on course duration. Although both mentors believe additional time would allow students to better develop their solutions through trial and error and further reflections, the public health mentor believes that lengthening the course will have it lose its immersive and intensive nature, which are important elements of the experience. We plan to interview more mentors in order to further validate the findings.

\section{RECOMMENDATIONS AND FUTURE WORK}

The iterative process followed by the organizing team, as mentioned above, helped lay down elements that could lay the foundations of inter-faculty service learning courses across disparate disciplines. This paper shows that the combination of following components allowed for a successful humanitarian engineering course:

- Modular learning (context, needs assessment, design, prototyping, pitching): splitting the course's learning outcomes into chronological modules helps maintain a logical structure and pace to the course while incorporating the various disciplines;

- Intertwined session types including lectures, small-group discussions, mentoring, fieldwork, and activities: this allows students to directly apply what they are learning and get immediate and continuous feedback and guidance throughout the course;

- Participatory active learning: students need to have a proactive approach to the course, as they are responsible for developing a tangible output with potential impact. The majority of course lessons are activities, mentoring sessions and fieldwork heavily engaging students;

- Intensive and immersive learning experience: the course is offered in a short and condensed format. Students cannot take any other course at the same time and are expected to commit themselves for at least 8 hours a day for the duration of the course. The equivalent of 3 credit course is offered in the span of 3 weeks;

- Multidisciplinary teamwork: throughout the course, students work in multidisciplinary teams allowing students to learn from each other and to gain the professional skill of working in teams with very different backgrounds (engineering, health, social sciences, etc). 
Based on the work described, the organizing team also believes that there is room for continued improvement. The developed model can be further enhanced by:

- Better allocation of time for the different course modules and giving prototyping more time,

- Drawing more emphasis on the thought process of devising feasible and scalable solutions with real world impact,

- Increasing technical support to students to compensate for the diverse backgrounds.

It is worth noting that the course has been attracting far fewer men than women enrollees. Namely, only $36 \%$ of the second session's enrollees, $27 \%$ of the third session's enrollees, and $40 \%$ of the fourth session's enrollees were men. In fact, men have been shown to be attracted to engineering disciplines and women to the humanitarian field. ${ }^{6}$ Therefore, the inter-faculty course should emphasis its multi-disciplinary nature and further pursue the recruitment of men in order to have better gender balance.

\section{ACKNOWLEDGMENTS}

This work was supported in part by the American University of Beirut's Center for Teaching and Learning under Grant 3750, Faculty of Health Sciences, and Maroun Semaan Faculty of Engineering and Architecture.

\section{REFERENCES}

1. UNHCR, Protracted Refugee Situations, in EC/54/SC/CRP.14, S.C. Executive Committee of the High Commissioner's Programme, Editor. 2004.

2. D.E. Goldberg, The missing basics and other philosophical reflections for the transformation of engineering education, In Holistic Engineering Education. Eds. D. Grasso and M.B. Burkins, 2010, Springer, New York. p. 145-158.

3. B. Warin, C. Kolski, and M. Sagar, Framework for the evolution of acquiring knowledge modules to integrate the acquisition of high-level cognitive skills and professional competencies: Principles and case studies. Computers \& Education, 2011. 57(2): p. 1595-1614.

4. D. Berrett, Lectures still dominate science and math teaching, sometimes hampering student success. The Chronicle of Higher Education, 2012.

5. J. Smith, P. Compston, S. Male, C. Baillie, and J. Turner, Intensive mode teaching of a humanitarian engineering course to enhance service-learning. International Journal for Service Learning in Engineering, 2016. 11(2): p. 38.

6. B. Latimer, D.A. Bergin, V. Guntu, D.J. Schulz, and S.S. Nair, Integrating Model-Based Approaches into a Neuroscience Curriculum--An Interdisciplinary Neuroscience Course in Engineering. IEEE Transactions on Education, 2018(99): p. 1-9.

7. J. Kasper, J.A. Greene, P.E. Farmer, and D.S. Jones, All health is global health, all medicine is social medicine: integrating the social sciences into the preclinical curriculum. Academic Medicine, 2016. 91(5): p. 628-632.

8. J. Frenk, L.C., Z. A. Bhutta, J. Cohen, N. Crisp, T. Evans, et al., Health professionals for a new century: transforming education to strengthen health systems in an interdependent world. The Lancet, 2010. 376: p. 19231958.

9. L. P. Fried, M.D.B., R. Bayer, S. Galea, MPH education for the 21 st century: motivation, rationale, and key principles for the new Columbia public health curriculum. American Journal of Public Health, 2014. 104(1): p. 23-30.

10. M.H. Ba-Aoum, Comprehensive model for fostering humanitarian engineering education. Global Humanitarian Technology Conference (GHTC), 2016. 2016. IEEE. 
International Journal for Service Learning in Engineering, Humanitarian Engineering and Social Entrepreneurship Vol. 14, No. 2, pp. 16-32, Fall 2019

ISSN 1555-9033

11. M.G. Burnham, The 'systems approach'to human problems: How humanitarian engineering can help. Technology and Society, 2009. ISTAS'09. IEEE International Symposium on. 2009. IEEE.

12. A. Brown and E. Gregersen, Humanitarian Engineering, In Encycolpedia Britannica Academic. 2014.

13. Y. Tayler, Humanitarian Engineering : Innovative Approaches and Partnerships in Crisis Response. MENA Knowledge and Learning Quick Notes Series No. 157, World Bank, Washington D.C. 2016.

14. J.A. Leydens and J.C. Lucena. The problem of knowledge in incorporating humanitarian ethics in engineering education: Barriers and opportunities. Frontiers in Education Conference, 36th Annual. 2006. IEEE.

15. J.D.J. VanderSteen, Humanitarian Engineering in the Engineering Curriculum, PhD Dissertation, Department of Civil Engineering, Queen's University: Kingston, Ontario, Canada. 2008.

16. K. Mehta, 22. Penn State Humanitarian Engineering and Social Entrepreneurship Program. Annals of Entrepreneurship Education and Pedagogy_2014, 2014: p. 376.

17. D. Nieusma and D. Riley, Designs on development: engineering, globalization, and social justice. Engineering Studies, 2010. 2(1): p. 29-59.

18. A. Nassar, K. Holmes, and K. Mehta. Student outcomes of short-term international humanitarian engineering fieldwork. IEEE Frontiers in Education Conference (FIE). 2016. IEEE.

19. ABET, Criteria for Accrediting Engineering Programs. 2015: Baltimore, USA.

20. M.W. Ohland, M.L. Loughry, D.J. Woehr, L.G. Bullard, R.M. Felder, C.J. Finelli, R.A. Layton, H.R. Pomeranz, and D.G. Schmucker. The comprehensive assessment of team member effectiveness: Development of a behaviorally anchored rating scale for self-and peer evaluation. Academy of Management Learning \& Education, 2012. 11(4): p. 609-630.

21. C.G. Jorgensen, Social studies curriculum migration: Confronting Challenges. The Social Studies Curriculum: Purposes, Problems, and Possibilities, Ed. E.W. Ross, State University of New York Press, Albany, 2014.

22. B. Warin, O. Talbi, C. Kolski, and F. Hoogstoel, Multi-Role project (MRP): A new project-based learning method for STEM. IEEE Transactions on Education, 2016. 59(2): p. 137-146.

23. M. Lehmann, P. Christensen, X. Du, and M. Thrane, Problem-oriented and project-based learning (POPBL) as an innovative learning strategy for sustainable development in engineering education. European Journal of Engineering Education, 2008. 33(3): p. 283-295.

24. A. Bandura, Guide for creating self-efficacy scales. Self-efficacy beliefs of adolescents, Ed. F.J. Pajares \& T. Urdan, Information Age Publishing Inc., 2006. p. 307-337.

25. K. Scoles, N. Bilgutay, and J. Good, A new course evaluation process. IEEE Transactions on Education, 2000. 43(2): p. 125-131.

26. I. Cabrera, J. Villalon, and J. Chavez, Blending Communities and Team-Based Learning in a Programming Course. IEEE Transactions on Education, 2017. 60(4): p. 288-295.

27. A. Bonarini and M. Romero, Robotics and Design: An Interdisciplinary Crash Course. IEEE Transactions on Education, 2013. 56(1): p. 110-115.

28. AUB. Humanitarian Engineering: Solutions for Health in Conflict. 2017 [cited 2018 September 4]; Available from: http://www.aub.edu.lb/msfea/Pages/he-summer2017.aspx.

29. I. H. ElHajj, Z.D., A. Germani, and H. Ghattas. Humanitarian engineering a health perspective. IEEE International Conference on Robotics and Automation. 2018. Brisbane, Australia.

30. AUB. Humanitarian Engineering: Designing Solutions for Health Challenges in Crises. 2018 [cited 2018 September 4]; Available from: http://www.aub.edu.lb/msfea/Pages/he-winter2018.aspx.

31. A.M. Kyle, D.C. Jangraw, M.B. Bouchard, and M.E. Downs, Bioinstrumentation: A Project-Based Engineering Course. IEEE Transactions on Education, 2016. 59(1): p. 52-58. 